Article

\title{
Problems with the Implementation of Industry 4.0 in Enterprises from the SME Sector
}

\author{
Manuela Ingaldi *(i) and Robert Ulewicz $(1)$ \\ Faculty of Management, Czestochowa University of Technology, al. Armii Krajowej 19b, 42-200 Czestochowa, \\ Poland; robert.ulewicz@wz.pcz.pl \\ * Correspondence: manuela.ingaldi@wz.pcz.pl; Tel.: +48-34-3250-426
}

Received: 3 November 2019; Accepted: 24 December 2019; Published: 26 December 2019

\begin{abstract}
Industry is currently undergoing a revolution (called Revolution 4.0) related to the far-reaching integration of all production areas through the digitization and the creation of new communication channels. The Polish economy generated a GDP of USD 524.5 billion in 2017, of which small and medium enterprises generated about $50 \%$ of revenue and in which microenterprises accounted for the largest share in generating GDP; i.e., around $30.2 \%$. The aim of the research is to determine the adaptation possibilities of the small and medium-sized enterprises (SME) sector to Industry 4.0 solutions. Pilot research was carried out in the Czestochowa Industrial District. Enterprises from the SME sector were asked to provide an information about the used technologies and to determine the level of their organization's readiness for sustainable development through technological transformation. Financial resources as well as a lack of specialized support in obtaining new technologies were defined as problems as far as transformation is concerned. The solution of the diagnosed problem is the development of a platform aimed at integrating the potential of enterprises from the SME sector in order to undertake joint actions for sustainable development.
\end{abstract}

Keywords: sustainability; Industry 4.0; SMEs; e-business modelling

\section{Introduction}

Each enterprise works in a turbulent environment. Such conditions apply to different spheres of business activity. It is important for an enterprise to observe such changes and, if necessary, to react accordingly. Only an appropriate reaction allows an enterprise to adapt to this situation. The global industrial landscape has changed dramatically over the past few years due to the rapid technological development and innovation in production processes [1]. In recent years, many initiatives have been launched for intelligent production in the world in order for a significant share of industry in the economy to be stored and regained [2,3].

In recent years, a new, large industrial revolution can be observed, affecting the functioning of enterprises in the market and resulting in different changes. This is the fourth wave of socio-economic evolution, called Industry $4.0[4,5]$. The development towards Industry 4.0 has a significant impact on the production industry. It presents the latest trends in automation technologies that are gaining popularity in the manufacturing industry. Additionally, Industry 4.0 has become a new topic for scientists dealing in disciplines such as management and business economics; thus, many publications on this subject have appeared [6]. Industry 4.0 seems to be one of the most promising ideas in terms of boosting industrialization and industrial competitiveness in EU countries [7].

The fourth industrial revolution differs from the previous ones because it applies to all aspects of our lives. Within its framework, industry processes and commercializes the exchange of information between people and between people and objects, as well as between the objects themselves [8]. Industry 4.0 gives the industry a new perspective that allows it to work with new technologies to achieve 
maximum efficiency with the minimal use of resources in the manufacturing industry. It affects the strategies and operations of enterprises, as well as the relationships between enterprises, customers and suppliers. In addition, decentralized production processes play an important role in Industry 4.0 through intelligent products that know their destinations, history, etc. [9].

The beginnings of Industry 4.0 stemmed from the strategy the German government started in 2013, focusing on achieving greater operational efficiency and productivity through automation. The first information about the Industry 4.0 concept appeared in 2014 at the World Economic Forum conference in Davos [10-12].

The horizontal and vertical integration of production systems are the foundations of Industry 4.0. These systems are based on real-time data exchange and flexible production to enable customized production $[13,14]$. The pillars of this evolution are, among others, the Internet of Things (allowing global access to data and machines coupled into the network), autonomous robots/systems (autonomy of production processes that allows for the full adjustment of production to the needs of the individualized market), cyber security, huge amounts of data fpr processing (analysis of big data sets, Big Data and Cloud Computing), additive printing (3D), advanced simulations, and virtual and extended reality $[8,15-18]$.

One of the main elements of Industry 4.0 is the Internet of Things. Since the end of the 20th century, it has been possible to observe the progressive digitization of everything that surrounds us, as well as the rapid development of the Internet. Currently, most European enterprises have access to the Internet, and many of them offer their products via the Internet. Due to global communication, products and components will be able to exchange data with any IoT devices, thus significantly expanding their functions [19]. Digital transformation has not only changed the way the organization works, but, as a result, the market is also transforming into a full value chain. Industry 4.0 causes essential changes to issues such as the economy, work environment and skill development [20].

Virtual and extended reality is yet another significant element of Industry 4.0. It allows the collection of large amounts of data and the creation of various types of platforms by a larger group of enterprises. It also facilitates the exchange of a variety of information by employees within one enterprise, but also within a group of enterprises. This exchange does not take place in the real world, but a virtual one, which can be accessed from different places in the world.

Such changes take into account certain elements related to the concept of sustainable development. From the environmental point of view, they allow for a smaller impact on the natural environment and better use of materials. From the economic point of view, however, they are associated with large financial expenditures, in particular the purchase of modern, highly developed machines, which for many enterprises is unfortunately impossible. Intelligent machines can reduce the demand for employees in the labor market, which indicates a social aspect. The growing trend in the literature towards sustainable development within the Industry 4.0 model highlights the importance of this topic, as well as various aspects that can be reliably resolved [21].

End-to-end engineering, which covers the entire product life cycle, should include an intelligent network and digitization relating to individual stages of the product life cycle: it should start from the raw material to the production system, then be applied to the use of the product, and only end with decommissioning [22].

Many researchers have contributed to the concept of Industry 4.0 by describing the theoretical aspects of this issue and then supporting them with practical solutions [12,22-28]. Nevertheless, there are many topics related to Industry 4.0 that require deeper analysis. One of these issues is linking Industry 4.0 with the concept of sustainable development, especially in the SME sector.

The development of enterprises using the assumptions of Industry 4.0 results in significant opportunities for implementing sustainable production, all due to the use of the omnipresent infrastructure of information and communication technologies (ICT). An important aspect in the time of the fourth industrial revolution is that the SME sector has not been destroyed; therefore, the doctrine of sustainable development is bound to work here. In current literature, it is an important 
determinant of the environmental dimension of sustainable development. Main resources such as products, materials, energy and water and their allocation can be implemented by smart-linked value creation modules [22]. Scientists still have to wait to determine how the implications of implementing Industry 4.0 will affect local and global economies. It should be pointed out that no more than $7 \%$ of research on Industry 4.0 focuses on the issue of sustainable development [1].

The industry has contributed to social welfare, which means that very high-quality products that meet virtually all customers' needs are produced, but at the same time, employees are also provided with the proper working conditions. Simultaneously, it can be observed that the current production structure still lacks adequate environmental sustainability. However, it is important that the industrial sector produces in an economically, environmentally and socially sustainable manner to achieve sustainable development [29].

Owing to Industry 4.0, new models of industrial management have been developed for small and medium-sized enterprises (SMEs). This concept, supported by, among others, numerous new technologies, is more flexible and cheaper compared to traditional IT systems used in enterprises; e.g., ERP (enterprise resource planning) and MES (manufacturing execution system). Unfortunately, small and medium-sized enterprises are insufficiently equipped to make use of the new opportunities that can aid production planning and control [30].

Sustainable development in the aspect of Industry 4.0 for the SME sector is, however, a very complex issue, not only from the technical point of view, but also from a non-technical standpoint; i.e., considering organizational factors and human resources. The generational change resulting from the natural state of affairs results in the appearance of employees with new competences and skills in the market, while, simultaneously, such abilities are often ahead of the adaptation possibilities of the technological infrastructure of the SME sector [7,31,32].

Such a situation can be observed in the research region. In total, $80 \%$ of the analyzed enterprises have problems with human resources. There are no specialists such as operators of universal devices available on the market. The available staff are able to operate advanced processing equipment which is unavailable for economic reasons for SMEs. This is the cause of the closure of economic activity by almost $80 \%$ of business entities that have opened their economic activity in the SME sector over the last three years [33].

Some of the production enterprises have changed into redistributive enterprises, outsourcing production-mainly to China, where they can deal with the real revolution of robotization and production automation resulting from the established priorities of the 5th Five Year Plan, as well as the objectives of the Made in China 2025 program. A considerable problem related to sustainable development in the SME sector, which is extremely noticeable due to economic factors and human resources, has been detected. It is possible to observe the liquidation of jobs and the transfer of production to China, where there is a large concentration of production and the exchange of the structure of business entities [34,35].

However, it should be emphasized that the Chinese market is also subject to dynamic changes and a significant increase in production robots per employee. In Poland, there are 20-30 robots per 10,000 employees. In the Czech Republic and Slovakia, this ratio is almost three times higher, and in Germany, this number is 10 times higher. In China, where there is a very rapid increase in wages, it is estimated that, by 2020, there will have been 100 robots per 10,000 employees. In 2017, the Digital Economy and Society Index (DESI) reported that Poland was 23rd in the group of 28 EU Member States. In 2016, 8.2\% of Polish enterprises used Cloud Computing services.

In order to maintain sustainable development in the SME sector of the metal industry, taking into account the economic factor, external funds should be obtained to change the technological equipment. There is, however, a problem related to the product portfolio, which may be unsatisfactory in relation to the new machinery. The production load may be insufficient to obtain a positive financial result.

The main aim of the conducted research is to analyze the level of automation and robotization and to assess the current state of enterprises from the SME sector and to check whether these enterprises 
would be interested in using modern communication channels based on the platform structure, enabling the optimization of the product portfolio of producers based on a consolidation and optimization of the investment strategy in terms of obtaining modern flexible technologies compliant with the Industry 4.0 standard.

In this article, the results of pilot research related to the impact of changes in Industry 4.0 on small and medium-sized enterprises in the Czestochowa Industrial District were presented.

This paper concerns a very important issue related to the implementation of Industry 4.0 in small and medium enterprises. The survey that was used for the study was created on the basis of the initial analysis (preliminary questionnaire and expert interview). The major problems related to the implementation of Industry 4.0 in enterprises of the SME sector which were mentioned most often by respondents have been summarized. The survey was created as a result of initial analysis and was sent to the research enterprises. The set of questions that were used in the research and which are presented in the paper can be used by other scientists for similar research. The results of the pilot research themselves, presented in this paper, indicate the level of encountered problems and may form the basis for further research carried out by other research centers.

The remaining part of the article is organized as follows: Section 2 presents the problem description, which was the basis for further research. Section 3 includes the presentation of the research materials and method. In Section 4, the main results with their discussion are presented, while in Section 5, the main conclusions of the paper are presented.

\section{Problems Description}

The Czestochowa Industrial District is the third largest industrial district of the Silesian Voivodship. The basis of this district is the metallurgical and metal industries. It should also be emphasized that, in this district, enterprises from the SME sector are the most numerous. In many cases, they are family enterprises which have been passed from generation to generation.

Many enterprises from this district are old and have a lasting tradition. They have established a reputation on the market and created a group of their own customers. Unfortunately, they are equipped with old devices, which often break down. Due to the low profit, low productivity and low production level, they cannot afford to buy new, modern machines which are already fully automated. Often, it may also turn out that, even if it was possible to buy a machine, it would not be economically viable, because the efficiency of such a machine would be too high for a given enterprise. Enterprises from the SME sector in Poland are poorly equipped in terms of both computers and Internet access.

Generally, all over the world, small and medium-sized enterprises often do not have sufficient funds to invest in the latest technologies and must allocate capital very effectively and carefully. [17,36]. Other problems are difficulties in hiring staff, the high cost of staff and big competition.

Old equipment is primarily a problem from the production and economic point of view for a given enterprise. Old machines often break down, require a great deal of renovation, are not very efficient and often cause incompatibilities from the point of view of employees and are also dangerous to use. This affects the costs of the enterprise's operation, especially the cost of repairs and thus result in high prices of the sold products. Moreover, old equipment also has a greater impact on the natural environment surrounding such enterprises, increasing waste and emissions to the atmosphere. It should be mentioned that Czestochowa and the surrounding area are part of the Cracow-Czestochowa Upland; i.e., green and tourist areas. However, there is a continuous increase in investment outlays for new and used fixed assets [37].

Another problem that is common in the whole country as well as in the region is the lack of employees. Currently, the employees more often dictate conditions and the employers try to convince them to work for them. This is due to the fact that many people, after Poland's accession to the European Union, left the country to look for a job abroad. Many of these people are qualified employees-specialists who were not satisfied with their salary in Poland. Consequently, there are 
almost no people who can handle specialized machines. The outflow of employees also affects the economics of the research region.

More and more employees from other countries are hired: employees from Ukraine, Turkey or Serbia, however, do not have all the necessary skills. Workers from China, despite having such skills, are, however, not very flexible, and the cost of their transport and stay in Poland is very high. Also, communicating with such employees poses a problem as most of them do not speak Polish, and they often do not even know any of the congress languages, which would facilitate communication. It should also be emphasized that the Polish language is one of the most difficult to learn; furthermore, the forecasts indicate that many employees-for example, from Ukraine-may soon leave Poland to work in German enterprises due to the liberalization of the German labor market for that country.

One of the ideas that would help solve the above problems would be a platform in which several enterprises would buy machines together in order to reduce the purchase costs per enterprise and make better use of their production capacity. A group of employees should be employed to operate the machines, and both would be paid by all the involved enterprises on the basis of the capacity utilization. The platform could also offer sales of production capacities to other interested entrepreneurs, as well as taking advantage of the possibility of co-employing employees or exchanging information.

The idea of creating a platform is not new. It was used by other enterprises from other industrial sectors. In many cities in eastern Europe, stationary versions of such platforms are created; i.e. technology parks, special branches at industry chambers or clusters. They bring together enterprises with similar production and gather good practices and experience focused on specific industries. However, it should be checked whether the enterprises of the research region would be willing to take part in the described platform.

Research on Industry 4.0 in the SME sector has been conducted by scientists in other countries. According to Turkish researchers, most Turkish SMEs currently use sensor systems, automation and preventative maintenance. Nevertheless, at the same time, many enterprises do not have knowledge about the Internet of Things, additive (3D) production, augmented reality and large data. Most enterprises believe that high costs are unfortunately the main barrier to the implementation of Industry 4.0 technology. Research has also pointed out that SMEs need more information on the adoption of Industry 4.0 [38].

The Chinese government wants to build intelligent production systems that will become competitive on the global market and which will be at the level of ubiquitous information systems and communication systems. China's goal is to reduce their dependence on imported products by purchasing technologies for production; for example, in the automotive sector $[39,40]$.

European Member States and their individual regions are involved in adapting their innovation systems to the objectives of Industry 4.0, and Europe as a whole faces the challenge of striking a balance between elements such as promoting excellence in research and innovation, sustainable development and the positioning of less developed regions to make the most of the benefits of the ongoing industrial revolution [41].

The patronage of the European Union is a centralized guideline regarding the implementation of Industry 4.0. Several important programs have been created at the European level, but many European countries have come out with their own initiatives and their own funding objectives and programs. The US is working on technology for future production. The consortium also includes important German companies such as Siemens and Bosch. The main focus is on IoT and the connection of future factories. According to Industry 4.0, production should be more efficient while value-added processes should be optimized. In addition, enterprises want greater machine availability as well as a high level of customized production [39].

Researchers from Estonia emphasize the relationship between networking, organizational development, structural framework conditions and sustainable development in the context of Industry 4.0. Many production facilities never develop a mature organizational culture, so employees often 
lack a common organizational way of thinking, which may cause organizational inefficiencies in the production plant, as well as impede communication and cooperation [7].

\section{Methodology}

Pilot research was carried out in the production enterprises of the SME sector in the area of the Silesian Voivodship. The industry, which is located in this voivodship, has been experiencing huge changes in recent years. Previously, this was a region in which mines and enterprises from the metallurgical industry predominated; currently, production companies prevail.

The results presented in this paper concern enterprises from the Czestochowa Industrial District. As a test sample, 200 business entities from the selected area were involved. The aim of the research was to identify areas and problems in the field of Industry 4.0 and to identify opportunities to find potential solutions in the field of Industry 4.0 for manufacturing enterprises from the SME sector. The classification for the research sample was a minimum of 10 years of production activity and the size of employment that classified the enterprise in the SME sector.

Based on the results of the preliminary questionnaire, supplemented by an expert interview, the main areas and problems in the case of enterprises of the SME sector from our region related to the implementation of solutions in the field of Industry 4.0 were defined. The solutions used in Germany have been adopted as a reference point. Activities related to the implementation of Industry 4.0 are supported at a government level, as evidenced by the implementation of the recommendations issued [42]. A special Internet platform has even been created [43]. Therefore, one should expect significant progress in these activities in the coming years. Previously defined problems and solutions used in Germany were the basis for the research presented in the paper.

The research consists of three stages (Figure 1): In the first part, the characteristics of the enterprises participating in the research were made and their current status was assessed. This stage had a form of a survey. The second stage took the form of an expert interview with the enterprises who agreed to share information on the problems in Industry 4.0 they had encountered. In the third stage, a survey was again used-this time, to assess the possibility of creating a platform to facilitate Industry 4.0. Both surveys were completed by the same enterprises (in an electronic way).

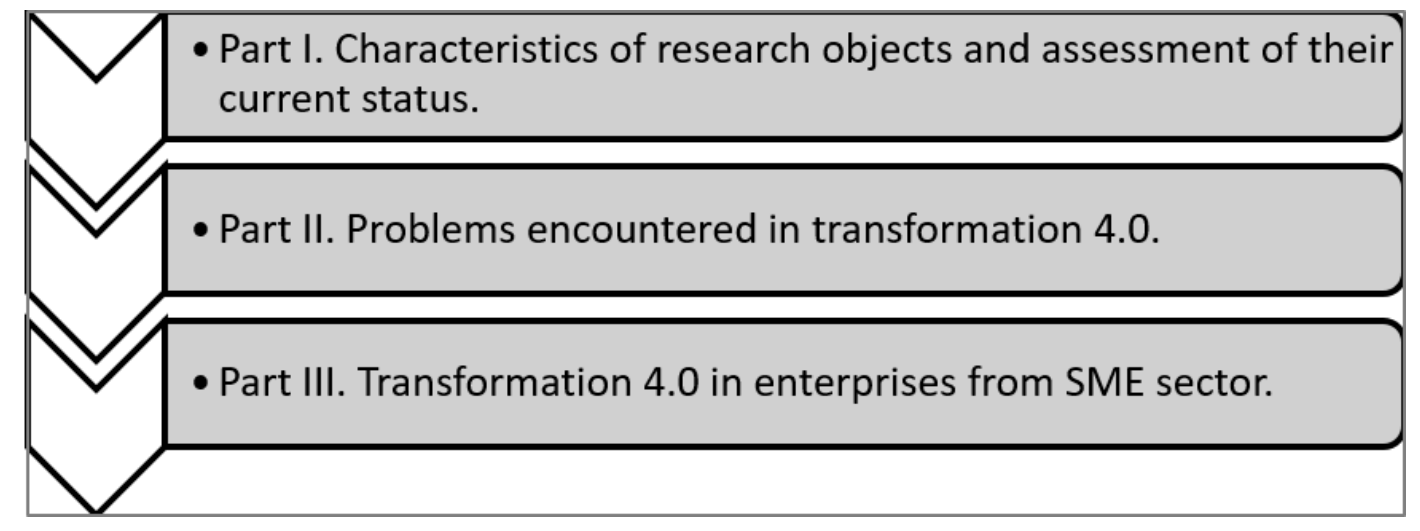

Figure 1. Stages of the research.

Part I. Characteristics of research objects and assessment of their current status.

This part concerned issues related to the type, form of production, automation and the used software. This part took the form of a questionnaire survey. This part of the research was conducted in spring 2018. The question area concerned the following:

1. Type of production organization used in the enterprise: unit, serial, mass-serial, mass;

2. The level of automation and robotization of production, assembly, transport and storage operations;

3. Use of industrial robots; 
4. Use of an autonomous transport system;

5. Use of the product modeling programs;

6. Use of the modeling production processes programs;

7. Use of the CIM system (Computer Integrated Manufacturing);

8. JIT (Just in Time) and KANBAN integration with suppliers and customer;

9. VSM (Value Stream Mapping) studies for the current state of the enterprise;

10. Measurement and monitoring of the value stream and the manner of performing these operations (manually, computer system);

11. Independence or integrating the operation of a computer system in an enterprise;

12. Use of the TPM method (Total Productive Maintenance);

13. Use of OEE indicators (Overall Equipment Effectiveness);

14. Identification of products, tools and materials in the system; e.g., the use of chips, bar codes or RFID (Radio-frequency identification);

15. Possibilities for sending commands directly by the system to particular elements;

16. Types of process database, database servers (own or Cloud) and their security;

17. Use of 3D printing technology during product prototyping;

18. Use of 3D printing technology during the production process;

19. Individualization of the product, mass customization and application of modular structure of products;

20. Use of $\mathrm{AI}$ or artificial intelligence in an enterprise.

Due to the fact that different rating scales were used, it was decided to use the methodology proposed by R. Kolman in quality engineering for the overall assessment of product quality [44]. For this purpose, one of the transformational methods was chosen-i.e., grading gradually (used for both measurable and non-measurable features) - and then the individual groups of responses were transformed to the interval (0.1), where 1 means the full modernity of the enterprise. In this way, it was possible to compare the responses and assess the overall current status of the research enterprises.

In the case of area 2, the respondents were asked to assess the level of automation and robotization of individual operations on a scale of $1-5$, where 1 meant manual machine processes and meant 5 full automation and robotization. Then, the assessments were transformed as follows: $1,0.1 ; 2,0.3 ; 3,0.5 ; 4$, 0.7, 5: 0.9 .

In the case of areas 3-10 and 12-20, respondents could indicate whether such an instrument is used in their enterprise, choosing one of the following responses: I do not know, no, sometimes, yes. In this case, the transformation was the following: I do not know, 0.1; no, 0.3; sometimes, 0.7; yes, 0.9 .

Additional information was obtained for areas 10 and 16. In area 10, people were asked whether metering and monitoring was carried out manually (0.3) or by a computer (0.9), while in the case of area 16, they were asked whether the enterprises' databases were their own databases $(0.3)$ or the Cloud (0.9). A separate scale was given to area 11. Enterprises were asked about the operation of a computer system: an independent system (0.3) or an integrated system (0.9).

Part II. Problems encountered in Industry 4.0.

The second part of the research took the form of an expert interview. It concerned the identification of obstacles and problems related to the use of various types of instruments aimed at modernizing the enterprise. This part of the research was conducted in summer and autumn 2018. The following questions were asked:

1. What are the obstacles associated with increasing the level of automation and robotization of production processes?

2. What are the obstacles associated with increasing the level of automation and robotization of warehouse processes? 
3. What are the obstacles associated with increasing the level of automation and robotization of transport processes?

4. What are the obstacles associated with the use of robots and process simulation programs?

5. Is there a need to monitor processes in real time?

6. What are the obstacles associated with the monitoring of the processes in real time?

7. Does the enterprise see the need to switch to a pull system and use JIT, KANBAN or other systems?

8. What are the problems associated with the implementation of JIT, KANBAN or other systems or on the side of the system itself, people or integration with external entities?

9. What are the problems with monitoring processes, documenting and selling data and their use in the field of process improvement and optimization?

10. What are the problems with the implementation and use of TPM?

11. What are the problems with monitoring and supervision over the material, product and tool during the process?

12. What problems did the enterprise encounter when individualizing the product?

Due to the fact that these were open questions, the grouping methodology proposed in the CIT method was applied $[45,46]$ and used in the assessment of the service quality, but without any division into positive and negative answers. The responses for individual areas were grouped according to their similarity, and so it was possible to indicate which responses (groups of responses) were the most common.

Part III. Industry 4.0 in enterprises from the SME sector.

Based on the expert interview and the most frequently indicated problems, a second questionnaire was developed to obtain the answer to whether creating a platform aimed at initiating activities to facilitate Industry 4.0 is justified in the opinion of entrepreneurs from the SME sector. Then, the survey was sent to companies that agreed to take part in the first research. The research was conducted from January to April 2019. The questions from the second questionnaire concerned the following:

1. The average age of owned production machines;

2. The production capacity in relation to the expectations and the level of its possible increase or the sale of a possible surplus;

3. Planning the purchase of new production equipment;

4. Problems related to planning the purchase of such equipment;

5. Possible problems with the number of employed employees and actions eliminating shortages in employment;

6. Willingness to participate in a platform that would bring together similar enterprises;

7. Willingness to share the purchase and use of machines within the platform;

8. Willing to co-employ employees within the platform;

9. Exchange of information regarding machines and employees within the platform;

10. Willingness to sell/buy production capacity as part of the platform;

11. Willingness to jointly develop a product within the platform.

The research was conducted among the enterprises whose headquarters are located in the Czestochowa Industrial District. The research was addressed to enterprises from the SME sector; however, large enterprises employing over 250 people were also included in the characteristics of the respondents. In this way, surveys completed by enterprises not from the SME sector could be eliminated. The results were obtained from 194 enterprises; however, seven of them were rejected.

In total, $28 \%$ of the surveyed objects were enterprises in which there was a unit type of production, $53 \%$ of respondents declared serial production, $8 \%$ mass-serial production, and $11 \%$ mass production. 


\section{Results and Discussion}

The analysis of pilot research in the field of evaluation of production entities in the aspect of preparation for Industry 4.0 allowed us to draw interesting results. The assessment of the current status of surveyed enterprises is shown in Figure 2.

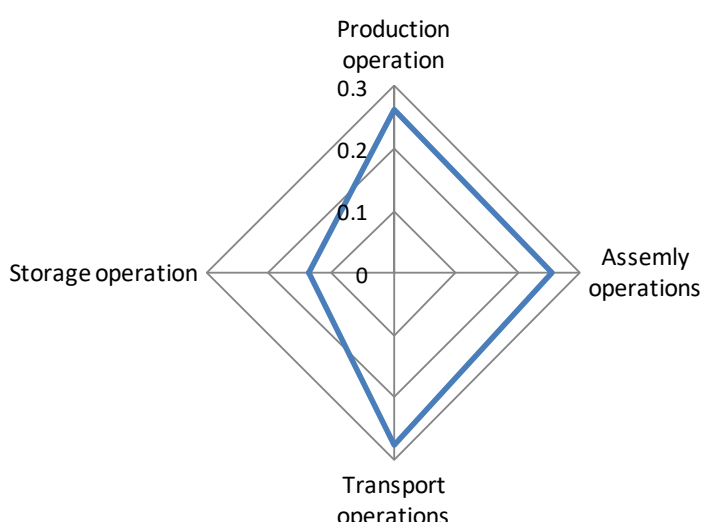

(a)

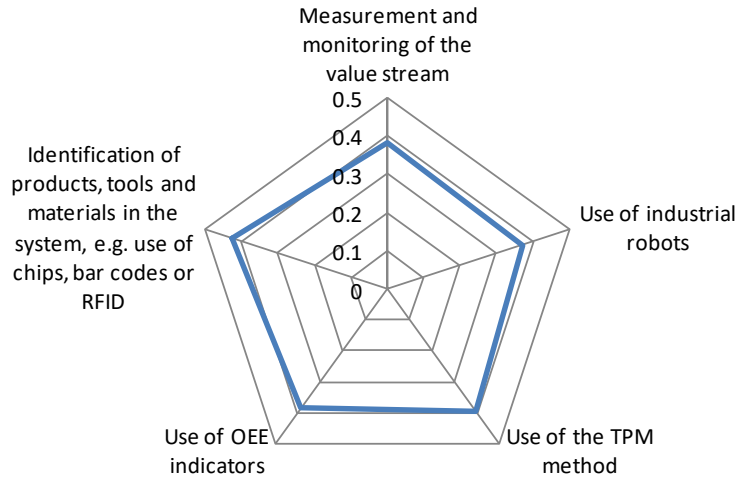

(c)

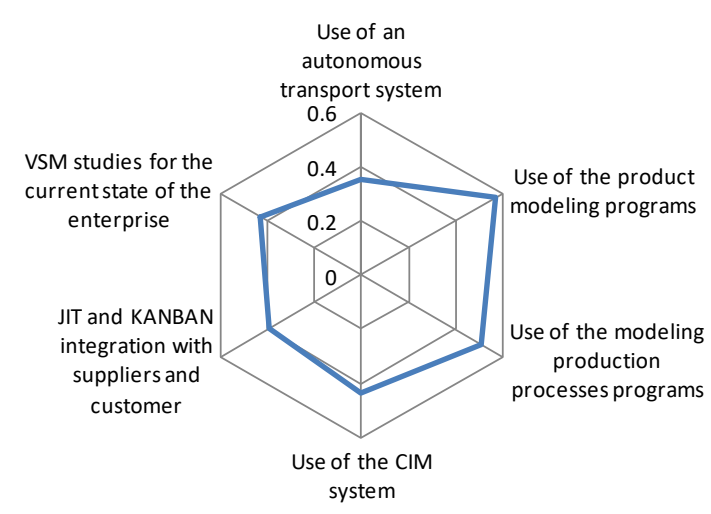

(b)

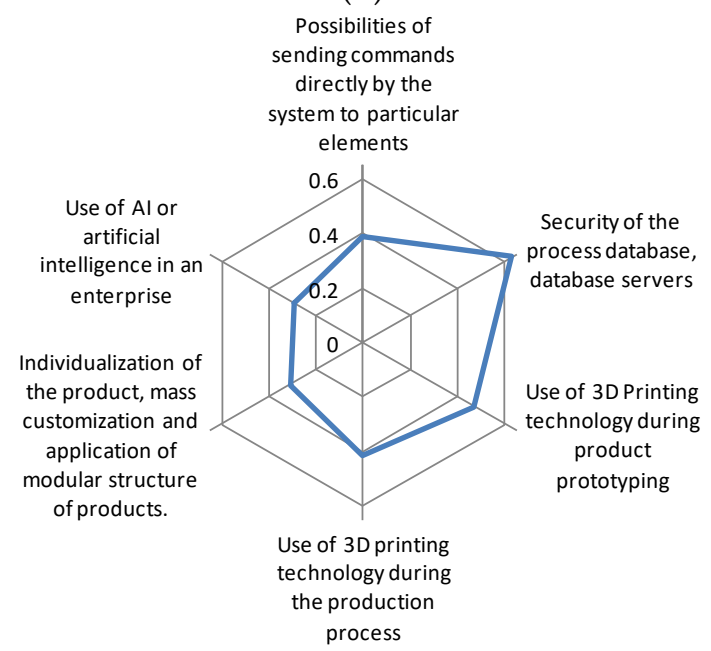

(d)

Figure 2. (a) The level of automation and robotization of individual operations; (b), (c), (d) assessment of the current state in the research enterprises.

From the analysis of Figure 2a, it can be concluded that the lowest level of automation and robotization among individual operations was recorded in the case of the storage operations (over 0.1 ). In the case of the other three types of operations, this level was similar but still low (about 0.3). The research enterprises are equipped with old, non-automated devices, which often break down. In general, the level of automation and robotization of Polish enterprises from the SME sector is lower than similar enterprises from other European Union countries.

Some of the research enterprises indicated that they sometimes use different programs for product modeling and for modeling production processes. They also secure process databases and database servers, but it should be emphasized that this results from the new provisions of the GDPR (General Data Protection Regulation) in force in the European Union.

Most instruments are used very rarely by a small number of enterprises. It was not known whether enterprises do not know these instruments or have problems using them. The expert interview examined the reason for this situation.

Summarizing the first part of the study, it can be pointed out that the average assessment of the current state of the surveyed enterprises of the SME sector in the range $(0 ; 1)$ is 0.38 , which is low. 
The research enterprises are equipped with old, non-automated equipment, which often breaks down. Only a few of them use a variety of instruments supporting production processes. Many of them have no idea about the existence of such instruments or do not know their names.

Based on the obtained results, it can be concluded that production systems in the SME sector are characterized by a low level of system integration as well as a low level of robotization and automation. This is mainly caused by the size of these enterprises and the lack of capital for investments.

The next part of the study (expert interview) concerned the identification of obstacles and problems related to the use of various types of instruments aimed at modernizing the enterprise. The most important results are presented in Figures 3-5.

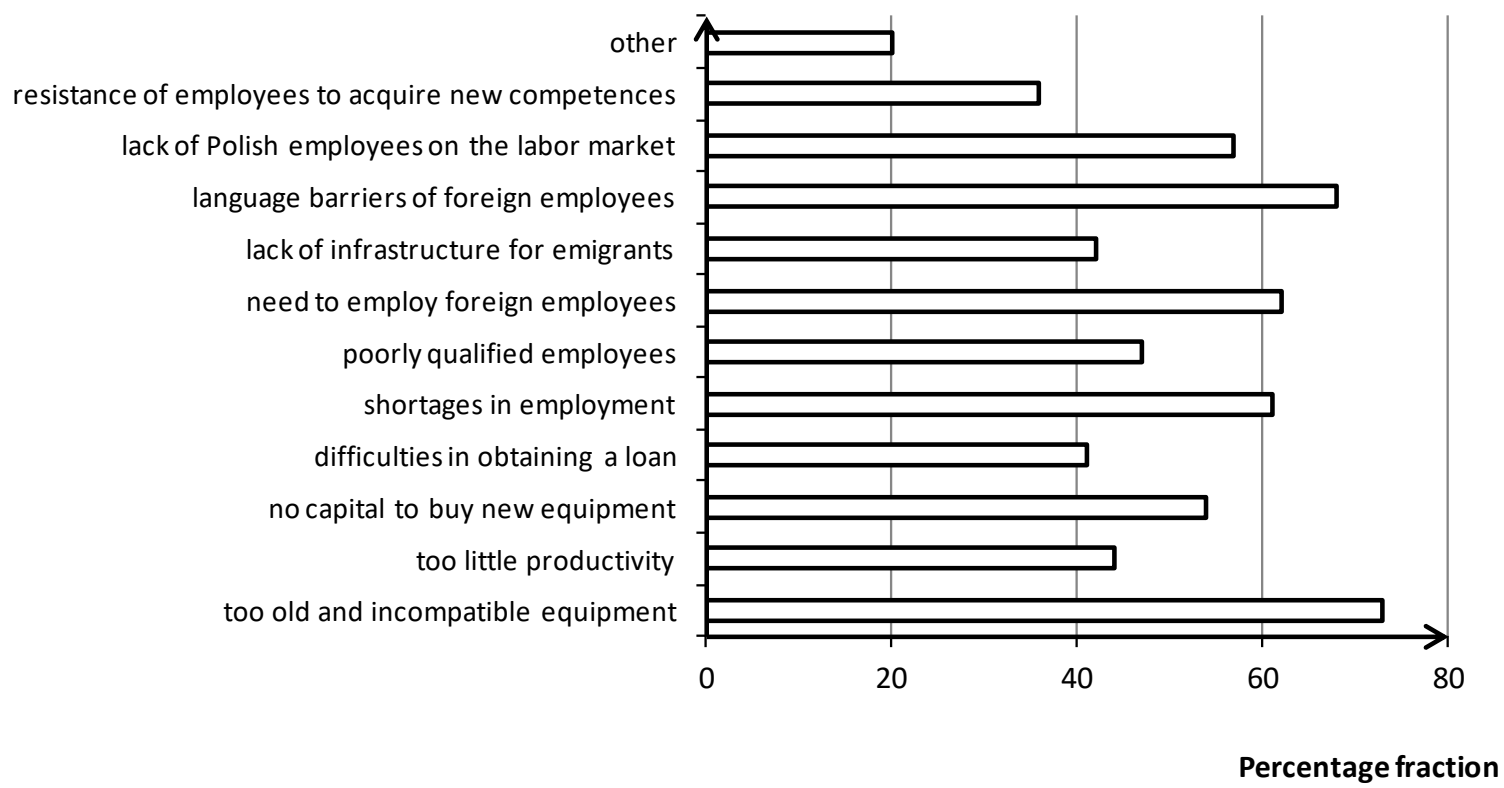

Figure 3. Obstacles associated with increasing the level of automation and robotization of different processes in enterprises.

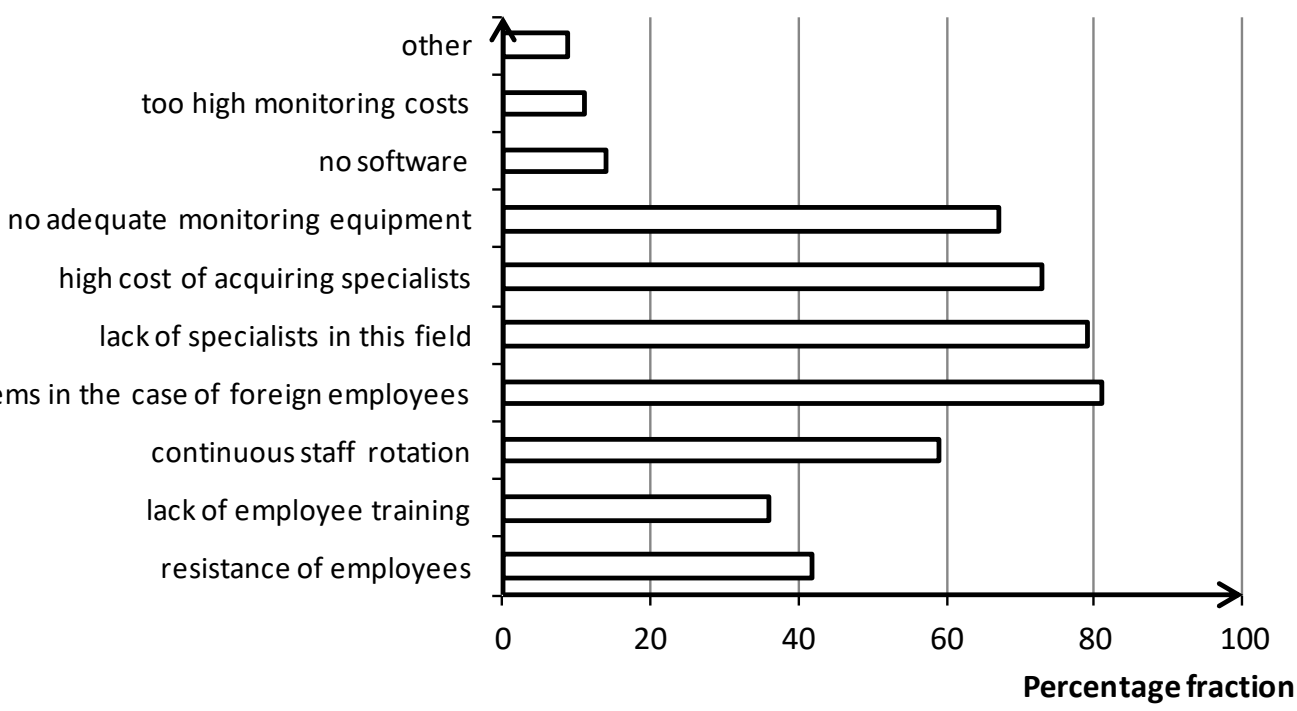

Figure 4. Problems with monitoring processes, documenting and selling data and their use in the field of process improvement and optimization, and monitoring and supervision of the material, product and tools during the process. 


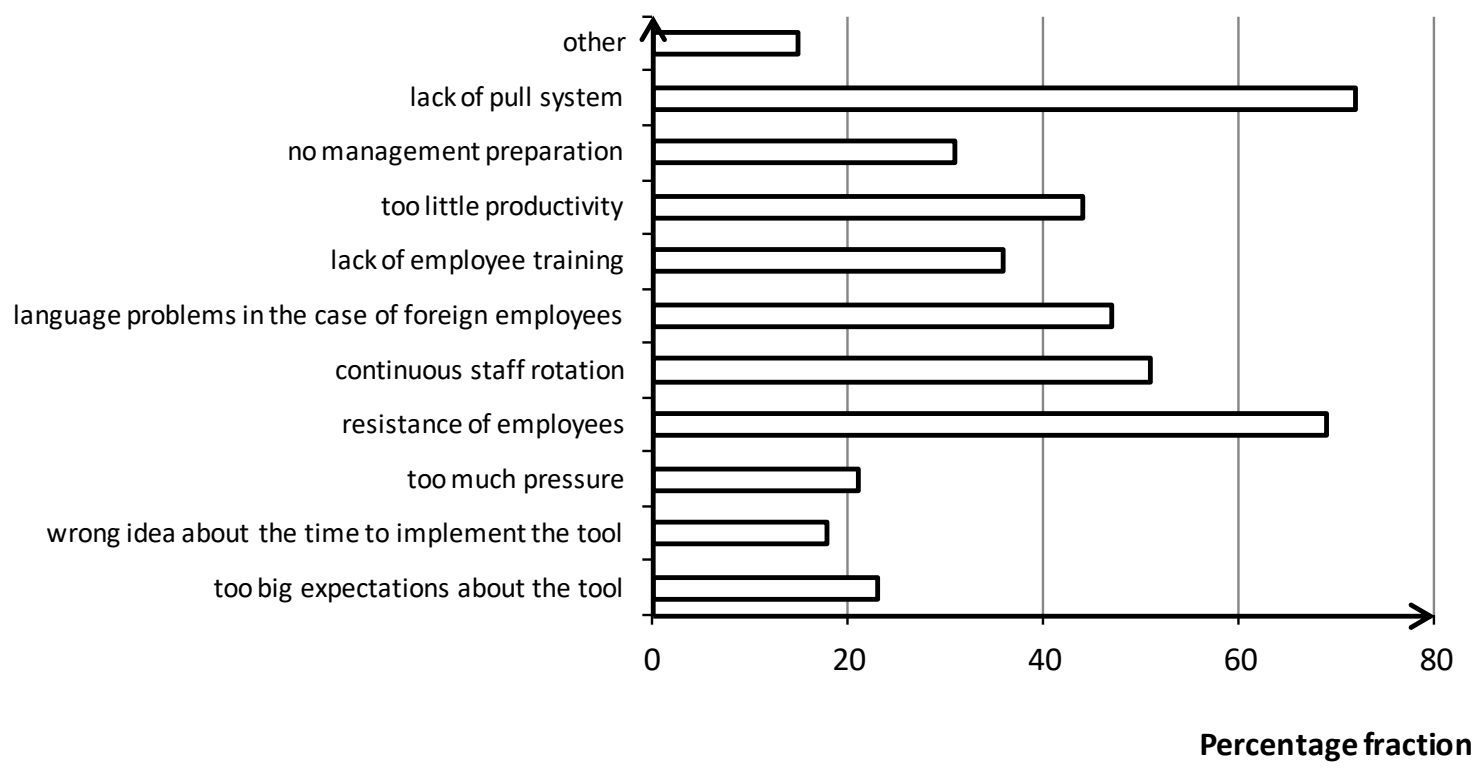

Figure 5. Problems when implementing various systems.

During the expert interview, the research enterprises showed that there is a need to monitor individual processes in real time. This is mainly related to the need to constantly control the course of these processes. These enterprises can also see the need to switch to a pull system and use JIT, KANBAN or other systems. This is related to the type of production that takes place in these facilities, which depends on the customers' orders and the sizes of these enterprises, because most enterprises from the SME sector cannot afford freezing capital.

The enterprises indicated many problems related to the implementation or use of various instruments aimed at improving their business. The resistance of employees is an important problem. Management must convince employees that changes are good and important and explain the need to implement them, but in the beginning, the same management must be convinced of such changes.

The problem with staff is a significant problem in Poland, including among research enterprises. It is an important social aspect of the functioning of enterprises, which determines the success of the entire enterprise and the introduced changes.

During the research, the enterprises pointed to the lack of specialists-operators who are able to handle the so-called analog production systems and the lack of specialists in the field of automation, robotics and IT. The employment of people especially from the second group is associated with high costs of obtaining and paying for this professional group.

Currently, enterprises hire specialists mainly from Turkey, Serbia and Ukraine; however, there are language barriers, sometimes cultural barriers, and a lack of infrastructure for foreign workers.

The results of the expert interview suggest that a certain solution may be the integration of SME sector production entities in the transition to Industry 4.0 through the development of a common product portfolio based on technological similarity. As a result, it is possible to reduce the costs of purchasing technical resources, reduce costs, and increase productivity through the optimal use of a universal machine park and greater individualization of the product.

The most important part of the research concerned the creation of a platform aimed at initiating actions to facilitate Industry 4.0 and especially its success among enterprises from SME sector. These results are shown in Figures 6-9. 


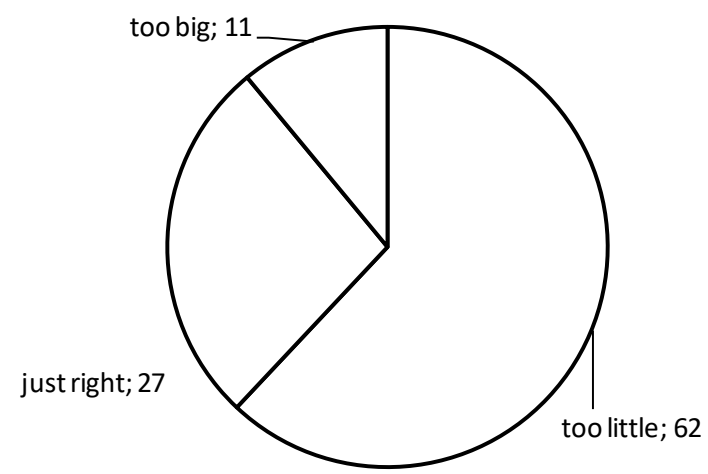

(a)

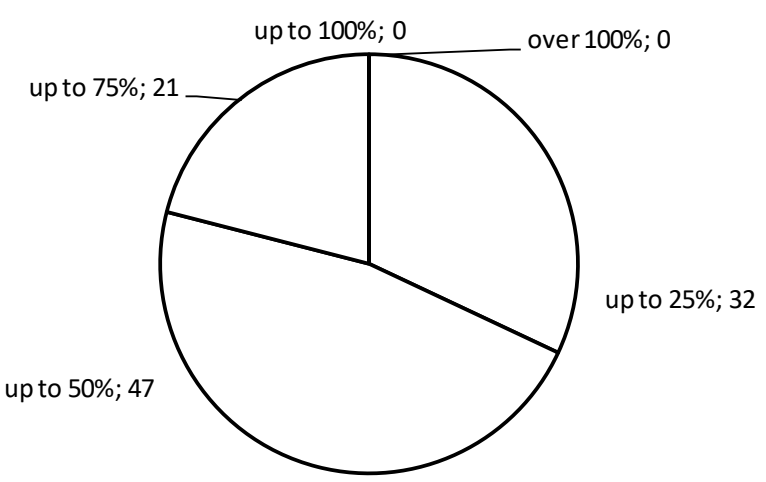

(b)

Figure 6. (a) Current production capacity in relation to the expectations of the enterprise; (b) if the production capacity is too small, then, how much would the enterprise like to increase it?

Only $27 \%$ of the research enterprises assessed their production capacity as just right. For $62 \%$, the production capacity was too small. $32 \%$ of respondents would willingly increase their production capacity to $25 \%$, and another $47 \%$ of respondents would increase their capacity even by up to $50 \%$. However, they are not able to do this at their own expense. All companies with overcapacity are interested in its possible sale, and those with too little production capacity are interested in its possible purchase.

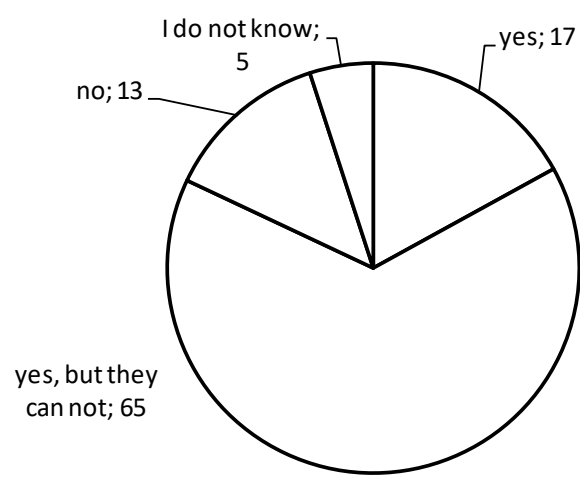

(a)

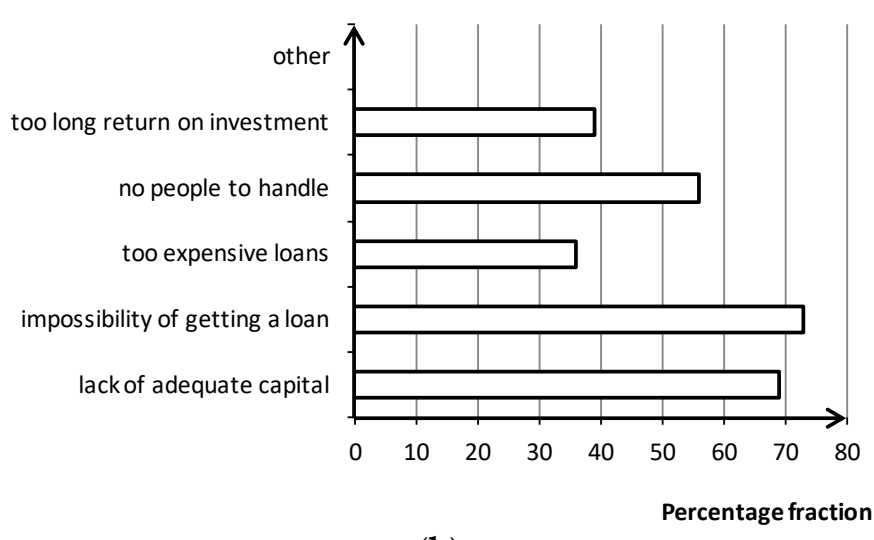

(b)

Figure 7. (a) Is the company interested in purchasing new equipment? (b) If they cannot, why? (possibly more than one answer).

Over $80 \%$ of all respondents were interested in purchasing new, more advanced equipment. Unfortunately, $65 \%$ of them, despite their willingness, were unable to do it. The most important reasons for this situation are the lack of adequate capital and the impossibility of obtaining a loan. Without the capital, the purchase of new equipment is not possible. 


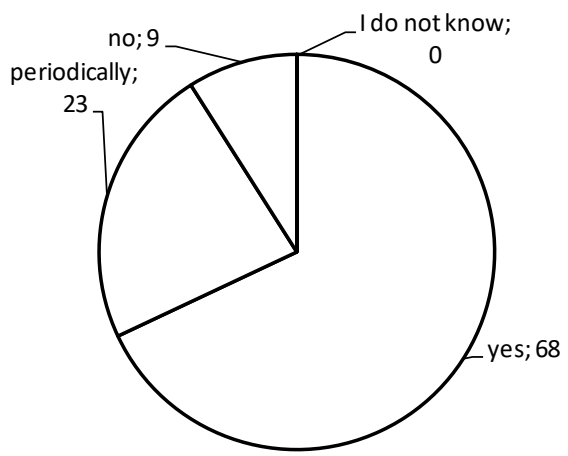

(a)

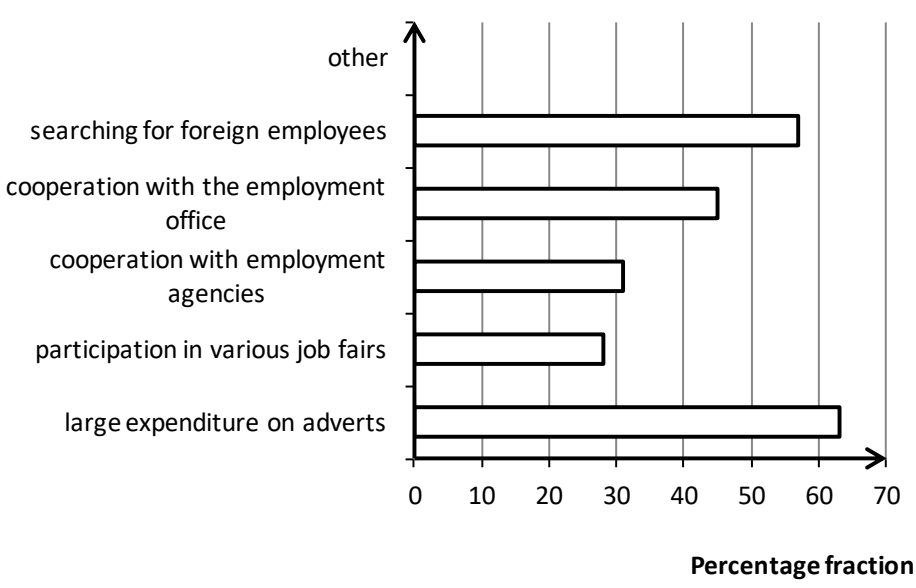

(b)

Figure 8. (a) Does the enterprise have problems with a lack of employees? (b) What is done in case of a lack of employees? (possibly more than one answer).

In total, $68 \%$ of respondents have problems with a lack of employees, while another $23 \%$ indicated the occurrence of this problem periodically. The enterprises are trying to solve this problem in various ways. Among the most common solutions were large expenditures on advertisements, searching for foreign employees and cooperation with employment offices.

It should be reminded that there is a lack of specialists in Poland. After Poland's accession to the European Union, there was a huge outflow of employees of all types from the domestic market, which resulted in the labor market changing from an employer's market to an employees' market. Perhaps these enterprises should be interested in cooperation with local high schools, universities, which could educate students in the subjects indicated by them.

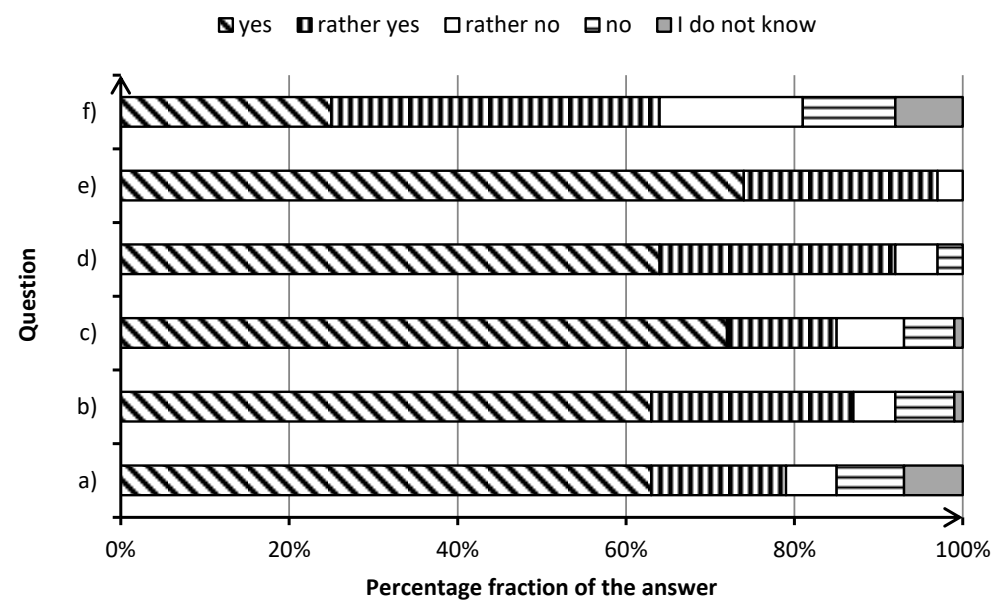

Figure 9. (a) Is the enterprise interested in taking part in a platform bringing together similar enterprises with similar problems? (b) Would the enterprise within such a platform be interested in the joint purchase and use of machines? (c) Would the enterprise within such a platform be interested in co-employing employees e.g. to operate these machines? (d) Would the enterprise within such a platform be interested in exchanging information on machines and employees? (e) Would the enterprise within such a platform be interested in selling/buying production capacity? (f) Would the enterprise within such a platform be interested in jointly development of a product?

In total, $63 \%$ of the research enterprises expressed their willingness to take part in a platform bringing similar enterprises with similar problems, while another $16 \%$ were also interested, although not completely sure of this decision. In total, $63 \%$ of respondents would be interested in the joint 
purchase and use of machines, while another $24 \%$ were not sure about this until the end. According to the respondents, co-employing employees would be a good idea $(72 \%$ answered yes and $13 \%$ inclined towards yes). This would help to solve problems with employment, especially regarding the employment of specialists. The enterprises were also interested in exchanging information on machines and employees within such a platform. An important point was the ability to sell/buy production capacity, which was declared by $74 \%$ of the research enterprises (plus $23 \%$ who were not entirely certain).

The enterprises were least interested in the joint development of products (only $25 \%$ of indications for yes, and 39\% were not entirely certain). This may be related to the fact that these enterprises belong to different industries and produce different products, or it is possible that these enterprises may also, despite their willingness to cooperate, want to remain competitive in the market.

From the conducted research, it can be concluded that enterprises from the SME sector from the Czestochowa Industrial District are focused on changes, but they cannot always afford them. However, if it were possible, they would like to cooperate with similar enterprises to invest in new equipment or employees.

\section{Conclusions}

As Herzog, Buchmeister, Beharic, et al. wrote [47], radical changes and transformations of various types of production systems, which are oriented on the assumptions of Industry 4.0, are possible mainly due to the development of disruptive technologies and the digital era. The fourth industrial revolution is a fact based on digitization; it has a variety of uses, from everyday tasks in the home to the automation of production processes. This industry is based on the systematic use of information technology. This situation is affected by many elements, including the development of automation, data processing and exchange, manufacturing techniques and the management organization of all processes. The key solutions that are used in Industry 4.0 can have a significant impact on the overall situation of the enterprise. The most important factors include increasing productivity and the availability of production resources, increasing equipment and production efficiency, and increasing value per employee [48].

However, it should be remembered that Industry 4.0 is not only about technology, but also about new ways of working and the role of people in industry. The Internet plays an increasingly important role in everyday life-not only of ordinary people, but above all of enterprises. E-enterprises are becoming more and more popular, which is caused by growing social awareness with relation to the role of the Internet. Activities that are undertaken by electronic means may reach a greater number of customers over a much faster time period and at a lower cost [49].

An important element which is often overlooked in the case of research on Industry 4.0 is sustainable development. It should be remembered that the structure of sustainable management can be introduced in different ways [50,51]. Two important elements of sustainable development are economics and society, from which it can be concluded that employees and their proper motivation are the key issue here.

Whether a management team successfully develops its enterprise and increases its competitiveness and income depends on many factors [52]. This is much more difficult for small and medium-sized enterprises, as enterprises in this sector have at their disposal less capital, fewer employees, less productivity, and less of much else besides. They may be supported in their effort by specific-oriented models [53], a deeper analysis of a process [54] and special technologies [55] or approaches [56,57] giving them a competitive advantage.

It is not easy for small and medium-sized enterprises to transform according to Industry 4.0. First of all, this is due to the economic aspect and the human factor. The product and technology portfolio available to small and medium enterprises is not adapted to the following industrial transformation. Therefore, they must look for solutions that, to some extent, may allow them to do this. 
In this paper, analyses of the level of automation and robotics, an assessment of the current state of enterprises from the SME sector and a verification of whether these enterprises would be interested in using modern communication channels based on the platform structure, enabling the optimization of the product portfolio of producers based on a consolidation and optimization of the investment strategy in terms of obtaining modern flexible technologies compliant with the Industry 4.0 standard, were presented. In this paper, the results of pilot research were included. This research took the form of a survey and expert interview. Pilot research was carried out in the Czestochowa Industrial District.

As a result of the conducted research, a hypothesis can be put forward, whose confirmation requires additional, further research. The determinants of implementing Industry 4.0 in the SME sector are difficult and demanding. The reason for this situation is the fragmentation of the technological and product portfolio in this sector, as well as the high level of costs of automation and robotization of production processes.

The human factor is another factor determining the effectiveness of the transformation process. Unlike in the case of China, where automation and robotization are perceived through the human-machine or the machine-human perspectives, in the research area presented in this paper, this process equals the loss of a job, hence the resistance of employees to making changes.

The summary of this research results is the determination of the three main barriers to Industry 4.0 in the SME sector. The first barrier is the narrow product portfolio of SMEs, which does not guarantee full use of the efficiency of automated and autonomous production systems. The second barrier is the cost of obtaining money; i.e., the funds for a given investment. An adverse condition is also the turbulence of the environment from the micro and macro aspect.

The results presented in the paper are not without limitations. The research survey was created on the basis of a preliminary survey and expert interview with a small group of enterprises of the SME sector. The authors could not find the main problems in the field of the Industry 4.0; therefore, some factor could have been omitted. Only the most important results are presented, and consequently, some elements might be overlooked, which may affect the understanding of the results. The pilot research will allow minor changes to be made to the survey form before proceeding to the next stage of the study.

The research presented in the paper will be continued in other parts of Poland and later will also be continued in other European countries. Additionally, the results of these research works will be compared with each other.

Author Contributions: Both authors participated equally in the preparation of this article. R.U. created the methodology; M.I. conducted the experiments. All authors have read and agreed to the published version of the manuscript.

Funding: This research received no external funding.

Conflicts of Interest: The authors declare no conflict of interest.

\section{References}

1. Maresova, P.; Soukal, I.; Svobodova, L.; Hedvicakova, M.; Javanmardi, E.; Selamat, A.; Krejcar, O. Consequences of Industry 4.0 in Business and Economics. Economies 2018, 6, 46. [CrossRef]

2. Maszke, A.; Dwornicka, R.; Ulewicz, R. Problems in the Implementation of the Lean Concept at a Steel Works-Case Study. In Proceedings of the 12th International Conference Quality Production Improvement-QPI 2018, Zaborze, Poland, 18-20 June 2018; EDP Science: Les Ulis, France, 2018.

3. Kleszcz, D. Barriers and opportunities in the implementation of lean manufacturing in the ceramic industry. Prod. Eng. Arch. 2018, 19, 48-52. [CrossRef]

4. Salvador, R.M.; de la Cruz, J.M. Presence of Industry 4.0 in additive manufacturing: Technological trends analysis. DYNA 2018, 93, 597-601. [CrossRef]

5. Thames, L.; Schaefer, D. Software-defined Cloud Manufacturing for Industry 4.0. Procedia CIRP 2016, 2, 12-17. [CrossRef] 
6. Piccarozzi, M.; Aquilani, B.; Gatti, C. Industry 4.0 in Management Studies: A Systematic Literature Review. Sustainability 2018, 10, 3821. [CrossRef]

7. Prause, G.; Atari, S. On sustainable production networks for Industry 4.0. Intern. J. Entrep. Sustain. Issues 2017, 4, 421-431. [CrossRef]

8. Ślusarczyk, B. Industry 4.0-Are We Ready? Pol. J. Manag. Stud. 2018, 17, 232-248. [CrossRef]

9. Kagermann, H.; Lukas, W.; Wahlster, W. Industrie 4.0: Mit dem Internet der Dinge auf dem Weg zur 4.0 industriellen Revolution. VDI Nachrichten 2011, 13, 2.

10. Strandhagen, J.W.; Alfnes, E.; Strandhagen, J.O.; Vallandingham, L.R. The fit of Industry 4.0 applications in manufacturing logistics: A multiple case study. Adv. Manuf. 2017, 5, 344-358. [CrossRef]

11. Liao, Y.; Deschamps, F.; Loures, E.D.F.R.; Ramos, L.F.P. Past, Present and Future of Industry 4.0—A Systematic Literature Review and Research Agenda Proposal. Int. J. Prod. Res. 2017, 55, 3609-3629. [CrossRef]

12. Lasi, H.; Fettke, P.; Kemper, H.G.; Feld, T.; Hoffmann, M. Industry 4.0. Bus. Inf. Syst. Eng. 2014, 6, $239-242$. [CrossRef]

13. Li, G.; Hou, Y.; Wu, A. Fourth Industrial Revolution: Technological Drivers, Impacts and Coping Methods. Chin. Geogr. Sci. 2017, 27, 626-637. [CrossRef]

14. Thoben, K.D.; Wiesner, S.; Wuest, T. Industrie 4.0 and Smart Manufacturing-A Review of Research Issues and Application Examples. Int. J. Autom. Technol. 2017, 11, 4-16. [CrossRef]

15. Pereira, A.C.; Romero, F. A review of the meanings and the implications of the Industry 4.0 concept. Procedia Manuf. 2017, 13, 1206-1214. [CrossRef]

16. Zhou, K.; Liu, T.; Zhou, L. August. Industry 4.0: Towards Future Industrial Opportunities and Challenges. In Proceedings of the 2015 12th International Conference on Fuzzy Systems and Knowledge Discovery (FSKD), Zhangjiajie, China, 15-17 August 2015; IEEE: Piscataway, NJ, USA, 2015.

17. Erol, S.; Jaeger, A.; Hold, P.; Ott, K.; Sihn, W. Tangible industry 4.0: A scenario-based approach to learning for the future of production. Procedia Cirp 2016, 54, 13-18. [CrossRef]

18. Wittenberg, C. Cause the trend industry 4.0 in the automated industry to new requirements on user interfaces? In Human-Computer Interaction: Users and Contexts. Lecture Notes in Computer Science; Kurosu, M., Ed.; Springer: Cham, Switzerland, 2015; Volume 9171, pp. 238-245.

19. Hitpass, B.; Astudillo, H. Editorial: Industry 4.0 Challenges for Business Process Management and Electronic-Commerce. J. Theor. Appl. El. Commer. Res. 2019, 14,1-3.

20. Sony, M. Industry 4.0 and lean management: A proposed integration model and research propositions. Prod. Manuf. Res. Open Access J. 2018, 6, 416-432. [CrossRef]

21. Bonilla, S.H.; Silva, H.R.O.; da Silva, M.T.; Goncalves, R.F.; Sacomano, J.B. Industry 4.0 and Sustainability Implications: A Scenario-Based Analysis of the Impacts and Challenges. Sustainability 2018, 10, 3740. [CrossRef]

22. Stock, T.; Seliger, G. Opportunities of Sustainable Manufacturing in Industry 4.0. Procedia CIRP 2016, 40, 536-541. [CrossRef]

23. Cheng, G.J.; Liu, L.T.; Qiang, X.J.; Liu, Y. Industry 4.0 development and application of intelligent manufacturing. In Proceedings of the 2016 International Conference on Information System and Artificial Intelligence (ISAI), Hong Kong, China, 24-26 June 2016; IEEE: Berrechid, Morocco, 2016.

24. Fonseca, L.M. Industry 4.0 and the digital society: Concepts, dimensions and envisioned benefits. In Proceedings of the International Conference on Business Excellence, Bucharest, Romania, 22-23 March 2018; Sciendo: Bucharest, Romania, 2018.

25. Kagermann, H. Change through digitization-Value creation in the age of Industry 4.0. In Management of Permanant Change; Albach, H., Meffert, H., Pinkwart, A., Eds.; Springer Gabler: Wiesbaden, Germany, 2015; pp. 23-45.

26. Rubmann, M.; Lorenz, M.; Gerbert, P.; Waldner, M.; Justus, J.; Engel, P.; Harnisch, M. Industry 4.0: The Future of Productivity and Growth in Manufacturing Industries; Boston Consulting Group: Boston, MA, USA, 2015; pp. 1-20.

27. Yen, C.T.; Liu, Y.C.; Lin, C.C.; Kao, C.C.; Wang, W.B.; Hsu, Y.R. Advanced manufacturing solution to Industry 4.0 trend through sensing network and Cloud Computing technologies. In Proceedings of the 2014 IEEE International Conference on Automation Science and Engineering (CASE), Taipei, Taiwan, 18-22 August 2014; IEEE: Piscataway, NJ, USA, 2014. 
28. Bertola, P.; Teunissen, J. Fashion 4.0. Innovating Fashion Industry Through Digital Transformation. RJTA 2018, 22, 352-369. [CrossRef]

29. Ingaldi, M.; Jursova, S. Economy and Possibilities of Waste Utilization in Poland. In Proceedings of the METAL 2013 22nd International Conference on Metallurgy and Materials, Brno, Czech Republic, 15-17 May 2013; TANGER Ltd.: Ostrava, Czech Republic, 2013.

30. Moeuf, A.; Pellerin, R.; Lamouri, S.; Tamayo-Giraldo, S.; Barbaray, R. The industrial management of SMEs in the era of Industry 4.0. Int. J. Prod. Res. 2018, 56, 1118-1136. [CrossRef]

31. Müller, J.M.; Voigt, K.I. Sustainable Industrial Value Creation in SMEs: A Comparison between Industry 4.0 and Made in China 2025. IJPEM-GT 2018, 5, 659-670.

32. Müller, J.M.; Buliga, O.; Voigt, K.I. Fortune Favors the Prepared: How SMEs Approach Business Model Innovations in Industry 4.0. Technol. Forecast. Soc. 2018, 132, 2-17. [CrossRef]

33. Glowny Urzad Statystyczny. Available online: www.stat.gov.pl (accessed on 10 August 2018).

34. Iskierka, S.; Krzemiński, J.; Weżgowiec, Z. Zapotrzebowanie rynku pracy na informatyków a praktyka dydaktyczna. Dydaktyka Informatyki 2017, 12, 33-42. [CrossRef]

35. Skwarska, A. Pracownicy z Ukrainy Odpowiedzią na Problemy Polskich Pracodawców? Available online: http://media.pracuj.pl/18776-pracownicy-z-ukrainy-odpowiedzia-na-problemy-polskichpracodawcow (accessed on 9 April 2018).

36. Bar, K.; Herbert-Hansen, Z.N.L.; Khalid, W. Considering Industry 4.0 Aspects in the Supply Chain for an SME. Prod. Eng. Res. Dev. 2018, 12, 747-758. [CrossRef]

37. Raport o Stanie Sektora Małych i Średnich Przedsiębiorstw w Polsce. Available online: https://www.parp. gov.pl/component/publications/publication/raport-o-stanie-sektora-msp-w-polsce-2017 (accessed on 11 October 2017).

38. Gergin, Z.; Üney-Yüksektepe, F.; Gençyılmaz, M.G.; Aktin, T.; Gülen, K.G.; İlhan, D.A.; Dündar, U.; Cebeci, O.; Çavdarl, A.I. Industry 4.0 Scorecard of Turkish SMEs. In Proceedings of the International Symposium for Production Research 2018, Vienna, Austria, 28-31 August 2018; Durakbasa, N.M., Gencyilmaz, M.G., Eds.; Springer: Cham, Switzerland, 2018.

39. Ehlers, N.; Loew, R.; Bleimann, U. Industry 4.0 national and international. In Proceedings of the Collaborative European Research Conference (CERC 2016), Cork, Ireland, 23-24 September 2016.

40. Overmaat, B. World Wide Race-Future of Production: Industrie 4.0 in Europa/Asien/USA. Available online: https://engineered.thyssenkrupp.com/world-wide-wettlauf-industrie-4-0-aktivitaeten-in-europeasien-usa (accessed on 9 April 2016).

41. Ciffolilli, A.; Muscio, A. Industry 4.0: National and Regional Comparative Advantages in Key Enabling Technologies. Eur. Plann. Stud. 2018, 26, 2323-2343. [CrossRef]

42. Kagermann, H.; Wahlster, W.; Helbig, J. Securing the Future of German Manufacturing Industry. Recommendations for Implementing the Strategic Initiative INDUSTRIE 4.0. Final Report of the Industrie 4.0 Working Group. Available online: https://www.din.de/blob/76902/e8cac883f42bf28536e7e8165993f1fd/ recommendations-for-implementing-industry-4-0-data.pdf (accessed on 19 December 2019).

43. Weyer, S.; Schmitt, M.; Ohmer, M.; Goreck, D. Towards Industry 4.0-Standardization as the crucial challenge for highly modular, multi-vendor production systems. IFAC-PapersOnLine 2015, 48, 579-584. [CrossRef]

44. Kolman, R. Inżynieria Jakości, 1st ed.; PWE: Warsaw, Poland, 1992; ISBN 978-83-2080-867-4.

45. Jubenville, T.; Cairns, S. An Introduction to the Enhanced Critical Incident Technique. Int. J. Qual. Methods 2016, 15,1 .

46. Ingaldi, M. Overview of the main methods of service quality analysis. Prod. Eng. Arch. 2018, 18, 54-59. [CrossRef]

47. Herzog, N.V.; Buchmeister, B.; Beharic, A.; Gajsek, B. Visual and optometric issues with smart glasses in Industry 4.0 working environment. Adv. Prod. Eng. Manag. 2018, 13, 417-428.

48. Resman, M.; Pipan, M.; Šimic, M.; Herakovič, N. A new architecture model for smart manufacturing: A performance analysis and comparison with the RAMI 4.0 reference model. Adv. Prod. Eng. Manag. 2019, 14, 153-165. [CrossRef]

49. Skowron-Grabowska, B.; Sukiennik, K. Innovations in e-enterprises on the Polish market. Procedia Comput. Sci. 2015, 65, 1046-1051. [CrossRef]

50. Grabara, J. The another point of view on sustainable management. Qual. Access Success 2017, 18, 344-349. 
51. Ingaldi, M.; Ulewicz, R. How to Make E-Commerce More Successful by Use of Kano's Model to Assess Customer Satisfaction in Terms of Sustainable Development. Sustainability 2019, 11, 4830. [CrossRef]

52. Dobes, K.; Kot, S.; Kramolis, J.; Sopkova, G. The Perception of Governmental Support in The Context of Competitiveness of SMEs in the Czech Republic. J. Compet. 2017, 9, 34-50. [CrossRef]

53. Pietraszek, J.; Gadek-Moszczak, A.; Torunski, T. Modeling of Errors Counting System for PCB Soldered in the Wave Soldering Technology. Adv. Mater. Res. 2014, 874, 139-143. [CrossRef]

54. Sygut, P.; Klimecka-Tatar, D.; Borkowski, S. Theoretical analysis of the influence of longitudinal stress changes on band dimensions during continuous rolling process. Arch. Metall. Mater. 2016, 61, 183-188. [CrossRef]

55. Zorawski, W.; Chalys, R.; Radek, N.; Borowiecka-Jamrozek, J. Plasma-sprayed composite coatings with reduced friction coefficient. Surf. Coat. Technol. 2008, 202, 4578-4582. [CrossRef]

56. Gadek-Moszczak, A. History of stereology. Image Anal. Stereol. 2017, 36, 151-152. [CrossRef]

57. Gadek-Moszczak, A.; Radek, N.; Wronski, S.; Tarasiuk, J. Application the 3D Image Analysis Techniques for Assessment the Quality of Material Surface Layer Before and After Laser Treatment. Adv. Mater. Res. 2014, 874, 133-138. [CrossRef]

(C) 2019 by the authors. Licensee MDPI, Basel, Switzerland. This article is an open access article distributed under the terms and conditions of the Creative Commons Attribution (CC BY) license (http://creativecommons.org/licenses/by/4.0/). 